\title{
The dynamic relationship between stock returns and trading volumes in Nepalese stock market
}

\begin{abstract}
In finance, the relationship between stock returns and trading volume has been the subject of extensive research over the past years. The main motivation for these studies is the central role that trading volume plays in the pricing of financial assets when new information comes in. As being interrelated and interdependent subjects, a study regarding the trading volume and stock returns seem to be vital. It is a well-researched area in developed markets. However, very few pieces of literature are available regarding the Nepalese stock market that explores the association between trading volume and stock return. Realizing this fact, this paper aims to examine the empirical relationship between trading volume and stock returns in the Nepalese stock market using time series data. The study sample is comprised of 49 stocks traded on the Nepal Stock Exchange (NEPSE) from mid-July 2011 to mid-July 2018. This study examines the Granger Causality relationship between stock returns and trading volume using the bivariate VAR model used by de Medeiros and Van Doornik (2008). The study found that the overall Nepalese stock market does not have a causal relationship between trading volume and return on the stock. In the case of sector-wise study, there is a unidirectional causality running from trading volume to stock returns in commercial banks and stock returns to trading volume in finance companies, hydropower companies, and insurance companies. There is no indication of any causal effect in the development bank, hotel, and other sectors. This study also finds that there is no evidence of bidirectional causality relationships in any sector of the Nepalese stock market.
\end{abstract}

Key Words: Trading volume, stock returns, Nepal Stock Exchange, Granger Causality test

\section{Introduction}

The dynamic relationship between Stock Returns and Trading Volume has been studied in various financial markets. In recent financial studies, this relationship has become a central issue as it provides insights into the microstructure of financial markets. The relationship between stock returns and trading volume can form the basis of profitable trading strategies, and it has implications for market efficiency (Chen, Firth, \& Yu, 2004). Stock returns and trading volume are two variables that are routinely released in the media to report on the status of the financial markets and are closely monitored by investors. Market participants believe

* Lecturer, Padmakanya Multiple Campus, PhD Scholar, Faculty of Management, Tribhuvan University E-mail:pladhikari2014@gmail.com 
that basic knowledge of stock returns and trading volume will enhance their understanding of the dynamics of the market and thus their financial success.

In finance, the relationship between stock returns and trading volume has been the subject of extensive research over the past years. The main motivation for these studies is the central role that trading volume plays in the pricing of financial assets when new information comes in. That is, the trading volume does not only play a significant role in market information but also reflect information about changes and agreement in investors' expectations (Harris and Raviv, 1993). Wang (1994) and He and Wang (1995) established a model based on asymmetric information and showed that trading volume is related to market information flow, and investors' private information. Chordia and Swaminathan (2000) also studied the predictability of short-term stock returns based on trading volume and concluded that high trading volume stocks respond promptly to market-wide information. Therefore, the literature widely uses volume as a proxy for information arrival.

Most studies on the relationship between stock return and trading volume applied in developed financial markets, there are very few studies in emerging financial markets, like Nepal. This study aims to contribute to the literature by investigating the relationship between trading volume and stock return volatility in the Nepal Stock Exchange (NEPSE) utilizing a relatively more recent database including individual stocks instead of a general stock index.

Until now we've focused mainly on the contemporary relationship between trading volume and stock returns. This study further extends the analysis by examining the causal (Dynamic) relationship. Causality testing is important since it can help to better understand the microstructure of stock markets and can also have implications for the markets.

\section{Statement of the problem}

The movements in the stock market are difficult to understand and forecasting is even more difficult. This necessitates empirical analysis. Various models have been used to explain the price-volume relationship in financial markets. A positive relation between return and volume is widely recognized in the finance literature. These include Sequential arrival models(Copeland 1976, Morse 1980, and Jennings and Barry,1983), a mixture of distribution model(Clark,1973, Epps and Epps, 1976, Tauchen and Pitts, 1983, and Harris, 1986, and Lamoureux and Lastrapes, 1990), asymmetric information models(Kyle, 1985) and the difference in opinion models (Varian,1985,\&1989). Some other studies report bidirectional causality between volume and return (Smirlock and Starks, 1988, Hiemstra and Jones, 1994, Ratner and Leal, 2001). Pisedtasalasai and Gunasekarage (2007) found unidirectional causality running from a stock return to trading volume for Indonesia, Malaysia, Singapore, and Thailand, and a significant causality running from trading volume to stock returns was detected only for Singapore. These studies have found that trading volume is related to information flow in the market and investors' public and private information is revealed through trading volume. 
The recent development of the Nepalese stock market has shown that investors' attraction towards the stock market can increase if we have an informational efficient financial market. Small and medium-sized investors can only be motivated to save and invest in the stock market when their securities are properly priced on the market. The stock market efficiency is determined by the information content of events and their dissemination. That is how quickly and correctly security prices reflect this information show the efficiency of the stock market. As being interrelated and interdependent subjects, studies regarding the trading volume and stock returns seem to be vital. It is a well-researched area in developed markets. There is very little literature available regarding the Nepalese stock market to explore the link between trading volume and stock return. Realizing this fact, the study aims to examine the relationship between trading volume and stock returns of the Nepalese stock market. Thus, the study deals with the following issues:

1. Is there unidirectional causality running from the stock return to trading volume?

2. Is there unidirectional causality running from trading volume to stock return?

3. Is there a bidirectional causal relationship between trading volume and stock return?

\section{Objectives of the study}

The main purpose of this study is to examine the Granger Causality relationship between stock returns and the trading volume for whole sample companies and sector-specific sample companies. Some specific objectives of this paper are as follows:

1. To examine whether there is a unidirectional causality running from the stock return to trading volume or from trading volume to stock return.

2. To investigate whether there is a bidirectional causal relationship between trading volume and stock return or not.

\section{Literature review}

Several theoretical and empirical models were developed in the past to explain the relation between stock return and the volume of trading. Based on a company's available set of information, its current stock price reflects the investors' expectations of those firms' future performance. The advent of new information causes investors to change their expectations and is the main source of information. Since investors are heterogeneous in interpreting new information, however, prices may remain unchanged even if new information is disclosed to the market. It will be the case if some investors interpret it as good news, while others see it as bad news, so differences in investor price reactions are usually lost through price averaging (Mestel, Gurgul, and Majdosz, 2005).

The MDH was first developed by Clark (1973) and it was later generalized by Epps and Epps (1976), Tauchen and Pitts (1983), Lamoureux and Lastrapes (1990) and Andersen (1996). This hypothesis argues that stock returns are generated by a mixture of distributions and information arrival is the mixing variable. Clark states that stock returns and trading volume 
are related due to common dependence on a latent information flow variable. This implies that price and volume change simultaneously in response to new information. According to Clark, the more information that comes into the market within a given time interval, the more strongly the prices of stocks tend to change. As information arrival is unobserved, the author advises using the volume data as a proxy of information flow into the market. Any unforeseen information contemporaneously affects both volatility and volume. This model implies strong positive contemporaneous but no causal linkages between trading volume and returns volatility data. It shows that the time series of market returns is not derived from a single probability distribution but from a mixture of conditional distributions with varying degrees of efficiency in producing the expected return (Girard and Biswas, 2007).

Fama (1970) did a study based on the efficient market hypothesis assuming that the information is systematically distributed in the market. Since in an efficient market, the prices adjust to new information quickly, so any current information cannot be used to predict future prices. The causality of volume on price is not possible in the efficient market framework.

Karpoff (1987) built a model that provides three reasons. First, the relationship between returns and trading volumes provides insight into the financial market structure. Secondly, the relationship between trading volume and stock return is important for event studies that use a combination of stock returns and trading volume data to draw inferences. Third, the relationship between return and trading is critical to the debate about the empirical distribution of speculative prices, which depends on asymmetries in the cost of going long or short. Costly short sales restrict some investors from acting on their information so their demands decrease. This effect decreases the variance of interfered shifts in transaction supply relative to that for transaction demand. In turn, this shift generates a positive covariance between trading volume and price change over the period. In a framework in which Blume, Easley, and Hara (1994) assumed stochastic fluctuations of stock prices and stated that data relating to the trading volume provide unique information to market participants; information which is not available from prices. The study argued that informed traders transmit their private information to the market through their trading activities. Uninformed traders can draw conclusions regarding the reliability of the information signals based on volume data.

Deo, Srinivasan, and Devanadhen (2008) examined the empirical relation between stock returns and trading volumes for selected Asia-Pacific stock markets. The study comprises of seven national stock markets (i.e. India, Hong Kong, Indonesia, Malaysia, Korea, Tokyo, and Taiwan) for the period spanning from 1st January 2004 to 31st March 2008. The study used the Vector Autoregressive (VAR) model to test the contemporaneous and causal relationship between trading volumes and stock returns. The Granger Causality Test was used to investigate whether the return is causing volume or volume to return. The results indicated a significant relationship exists between the volume of trading and the absolute value of price changes. The study suggested that the returns are influenced by volume and volume is influenced by returns for most of the markets. It indicates there is bidirectional causality between stock returns urns and trading volume in most of Asia-Pacific Stock Markets. Pisedtasalasai and 
Gunasekarage (2007) found statistically significant causality from the stock return to trading volume for Indonesia, Malaysia, Singapore, and Thailand, and only Singapore detected significant causality from trading volume to stock returns. For the Philippines, they did not find any causal effect.

Ravikant (2011) examined the relationship between stock returns and trading volume in India using monthly data time series over a nine-year period from January 2002 to December 2010 for three hundred forty-seven Indian stocks. The study used the three steps: first step descriptive study, the second step augmented dickey-fuller unit root test for stationery checking, and third step Granger causality tests to test the causality between stock return and trading volume. He found that there is high degree causality between stock return and trading volume in Indian stock market because out of three hundred forty-seven stocks, $66 \%$ stocks indicate that return cause volume, 3.3\% stocks indicate that volume cause return, 3.7\% stocks indicate bi-directional causation and the remaining $27 \%$ shows no causation at all. Thus, there is unidirectional causality from the stock return to trading volume in the Indian stock market.

Shrestha (2011) studied the relationship between stock returns and trading volume using daily data for the period of 2001 to 2009 with 55 sample firms' stocks listed in NEPSE. The study analyzed the contemporaneous relationship between stock returns and trading volume using the ordinary least square (OLS) regression equation, Unit root tests, and Augmented Dickey-Fuller (ADF) tests. Like most other studies, this study also found a positive relation between stock returns and trading volume.

\section{Methodology}

Research Design: This study has adopted a causal-comparative research design to determine the dynamic relationship between stock returns and trading volume. The study tests the granger casualty between trading volume and stock returns.

Nature and Sources of Data: The analysis of this study is mainly based on secondary data. The necessary information relating to monthly closing stock prices and the number of shares traded of selected listed companies were collected from periodical trading reports published by the Securities Board of Nepal (SEBON) and Nepal Stock Exchange Limited covering the period of seven years from Mid-July, 2011 to Mid- July 2018.

Population and Sample: In this paper, 196 total listed companies in the NEPSE till midJuly 2016 are considered as population. Out of them, 49 listed companies are selected as a sample which includes eighteen commercial banks, two hotels, six insurance companies, four finance companies, fourteen development banks, four hydropower companies, and one company from other sectors. Thus, the sample size is $25 \%$ of the total population. A total of 588 observations are used to examine the dynamic relationship between trading volume and stock returns. 
Analytical tools: The collected data are processed and analyzed based on software SPSS (Version 20) and MS-EXCEL. In this study, regression analysis with the F- test has been used.

Variables Specification: The study uses the volume series and the return series to examine the dynamic relationship between trading volume and stock returns. The total value of shares traded is used to measure trading volume for the study of aggregate trading activity. The total value of shares traded is the sum of the price of share traded times the Number of shares traded. The volume series at the time t noted as LOG $(\mathrm{v}-\mathrm{t})$ is expressed as:

\section{LOG $\left(\mathrm{V}_{\mathrm{t}}\right)$ - LOG (Volume)}

The volume series are non-stationary. The volume series are detrended to make series stationery. The detrended volume time series is defined as the difference between the actual trading volume and the estimated "normal" volume.

The study considered daily price changes as stock returns. A day-to-day price change is calculated using the natural log of the ratio of a stock's price $(\mathrm{P})$ from the current day $(\mathrm{t})$ to the previous day $(\mathrm{t}-1)$ as: $\mathrm{R}_{\mathrm{t}}=$ daily stock returns $=\operatorname{Ln}\left(\frac{P_{t}}{P_{t-1}}\right)$ Where, $\mathrm{P}_{\mathrm{t}}$ represents the closing price of the individual shares for the period $t, t$ is the time in days, $\mathrm{P}_{\mathrm{t}-1}$ is the closing price of the individual shares for the period $t-1, \operatorname{Ln}$ is the natural operator of the logarithm. All returns are expressed in local currencies and the dividends are not adjusted.

Model Specification: To test for Granger causality, we use a bivariate VAR model of order used by de Medeiros and Van Doornik (2008):

$$
\begin{aligned}
& R_{t}=\mu_{R}+\sum_{t=1}^{p} a_{j} \cdot R_{t-1}+\sum_{t=1}^{p} \beta_{j} \cdot V_{t-1}+\varepsilon_{t} \\
& V_{t}=\mu_{v}+\sum_{t=1}^{p} a_{j} \cdot \mathrm{V}_{t-1}+\sum_{t=1}^{p} \beta_{j} \cdot R_{t-1}+\varepsilon_{t}
\end{aligned}
$$

Where, $\varepsilon_{\mathrm{t}^{\prime}} \mu_{\mathrm{R}}$ and $\mu_{\mathrm{V}}$ are supposed to be independently and identically distributed processes with the model. The null hypothesis of $R_{t}\left(V_{t}\right)$ not to Granger-cause $V_{t}\left(R_{t}\right)$ implies that $\beta i(i=$ $1, \ldots, p)$ are all equal to 0 . To test the null, we calculate the F-statistic:

$$
F=\frac{S S E_{0}-S S E}{S S E} \cdot \frac{N-2 P-1}{P}
$$

Where $\mathrm{SSE}_{0}$ represents the sum of the square residuals of the restricted regression (i.e. $\beta_{1}=\ldots$ $=\beta p=0)$, SSE is the sum of the unrestricted equation 's square residuals and $\mathrm{N}$ denotes the number of observations. The F- statistic is asymptotic F distributed under the null hypothesis with $\mathrm{p}$ d.f. in the numerator and $(\mathrm{N}-2 \mathrm{p}-1)$ d.f. in the denominator. The parameters ai and $\beta \mathrm{i}$ in the equation are estimated by the use of OLS. To decide upon the appropriate order $\mathrm{p}$ of the VARs we used the corrected $\mathrm{R}^{2}$ and the Akaike information criterion (AIC). These are 
measures of goodness of fit that correct for the loss of d.f. resulting from adding additional lags to the model.

\section{Result and discussion}

The procedure used in this study for testing the statistical causality relationship between stock returns and trading volume is the 'Granger-causality' test, developed by C.W.J. Granger in 1969. The purpose of this test is to determine the predictive content of a variable beyond the explanatory variable itself. The Granger causality test requires the variables in the test to be stationary. According to the Granger representation theorem, if two variables say, $X_{t}$ and $Y_{t}$ are cointegrated and each is individually I (1), that is, integrated of order 1 , then either $X_{t}$ Granger-cause $Y_{t}$ or $Y_{t}$ Granger-cause $X_{t}$.

Table 1.1 : Summary statistics of granger-causality test

The variable volume $\left(V_{t}\right)$ is the log difference of trading volume in month $t$, and Stock returns are the signed value of stock returns. The Granger Causality test of whole sample firms and sector-wise sample firms are presented in panel I and panel II respectively. F-statistics of the Granger-causality test is shown for whole sample firms and sector-wise sample firms for the period of 2011 to 2018. P-values are in the parentheses.

\section{Null hypothesis:}

$\mathrm{V}_{\mathrm{t}}$ does not Granger Cause $\mathrm{R}_{\mathrm{t}}$ $\mathrm{R}_{\mathrm{t}}$ does not Granger Cause $\mathrm{V}_{\mathrm{t}}$

Panel I: WHOLE SAMPLE

\begin{tabular}{|l|l|}
\hline Null Hypothesis & $\begin{array}{l}\text { F-Statistic } \\
\text { (P-Value) }\end{array}$ \\
\hline$V_{t}$ does not Granger Cause $R_{t}$ & 0.84164 \\
& $(0.4350)$ \\
$R_{t}$ does not Granger Cause $V_{t}$ & 0.55046 \\
& $(0.5790)$ \\
\hline
\end{tabular}

Note: *** $1 \%$ or less, ${ }^{* *}$ up to $5 \%$, * up to $10 \%$ level significant

Panel II: SECTOR WISE SAMPLE

A. Commercial Bank

\begin{tabular}{|l|l|}
\hline Null Hypothesis & $\begin{array}{l}\text { F-Statistic } \\
\text { (P-value) }\end{array}$ \\
\hline$V_{t}$ does not Granger Cause $R_{t}$ & $8.04165^{* * *}$ \\
$R_{t}$ does not Granger Cause $V_{t}$ & $(0.0008)$ \\
0.42263 \\
$(0.6573)$
\end{tabular}


B. Development Bank

\begin{tabular}{|c|c|}
\hline Null Hypothesis & $\begin{array}{l}\text { F-Statistic } \\
\text { (P-Value) }\end{array}$ \\
\hline$V_{t}$ does not Granger Cause $R_{t}$ & $\begin{array}{l}0.52474 \\
(0.5938)\end{array}$ \\
\hline $\mathrm{R}_{\mathrm{t}}$ does not Granger Cause $\mathrm{V}_{\mathrm{t}}$ & $\begin{array}{l}1.47187 \\
(0.2360)\end{array}$ \\
\hline
\end{tabular}

C. Finance

\begin{tabular}{|l|l|}
\hline Null Hypothesis & F-Statistic \\
\hline$V_{t}$ does not Granger Cause $R_{t}$ & (P-Value) \\
& 0.75496 \\
$R_{t}$ does not Granger Cause $V_{t}$ & $(0.4735)$ \\
$3.19898^{* *}$ \\
\end{tabular}

Hotel

\begin{tabular}{|l|l|}
\hline Null Hypothesis & $\begin{array}{l}\text { F-Statistic } \\
\text { (P-Value) }\end{array}$ \\
\hline $\mathrm{V}_{\mathrm{t}}$ does not Granger Cause $\mathrm{R}_{\mathrm{t}}$ & 1.61706 \\
& $(0.2061)$ \\
$\mathrm{R}_{\mathrm{t}}$ does not Granger Cause $\mathrm{V}_{\mathrm{t}}$ & 0.31974 \\
& $(0.7274)$ \\
\hline
\end{tabular}

E. Hydropower

\begin{tabular}{|l}
\hline Null Hypothesis \\
\hline $\mathrm{V}_{t}$ does not Granger Cause $\mathrm{R}_{\mathrm{t}}$ \\
$\mathrm{R}_{\mathrm{t}}$ does not Granger Cause $\mathrm{V}_{\mathrm{t}}$
\end{tabular}

F-Statistic
(P-Value)
0.85337
$(0.4300)$
$3.18199 * *$
$(0.0471)$


F. Insurance

\begin{tabular}{|l|l|}
\hline Null Hypothesis & $\begin{array}{l}\text { F-Statistic } \\
\text { (P-Value) }\end{array}$ \\
\hline $\mathrm{V}_{\mathrm{t}}$ does not Granger Cause $\mathrm{R}_{\mathrm{t}}$ & 1.29785 \\
& $(0.2791)$ \\
$\mathrm{R}_{\mathrm{t}}$ does not Granger Cause $\mathrm{V}_{\mathrm{t}}$ & $3.27762^{* *}$ \\
& $(0.0431)$ \\
\hline
\end{tabular}

G. Other

\begin{tabular}{|l|l|}
\hline Null Hypothesis & $\begin{array}{l}\text { F-Statistic } \\
\text { (P-Value) }\end{array}$ \\
\hline $\mathrm{V}_{\mathrm{t}}$ does not Granger Cause $\mathrm{R}_{\mathrm{t}}$ & 0.94128 \\
& $(0.3955)$ \\
$\mathrm{R}_{\mathrm{t}}$ does not Granger Cause $\mathrm{V}_{\mathrm{t}}$ & 1.11128 \\
& $(0.3355)$ \\
\hline
\end{tabular}

Note: *** $-1 \%$ or less, ** up to $5 \%$, * up to $10 \%$ level significant

Table 1.1 reports the results of Granger causality tests between trading volume and stock returns. In the panel, I, the study the Granger causality test covers whole sample firms, and panel II covers sector-wise sample firms. The Granger causality from trading volume to stock returns is presented in the first row and the Granger causality from the stock return to trading volume is presented in the second row in every table. Both null hypotheses that volume does not Granger cause the stock returns and stock return do not Granger cause trading volume are accepted for whole sample companies in panel I. Thus, there is no causal relationship between stock returns and trading volume in overall Nepalese stock market. This result supports the findings of MDH model developed by Clark (1973) and later generalized by Epps and Epps (1976), Tauchen and Pitts (1983), Lamoureux and Lastrapes (1990), Andersen (1996) and Efficient Market Hypothesis developed by Fama (1970).

Panel II shows the results of the Granger causality test in the sector-wise sample firms. The null hypothesis that trading volume does not Granger cause stock return is rejected only for the commercial banks. It means there is a unidirectional causality running from trading volume to stock returns in commercial banks. The null hypothesis stock return does not Granger cause trading volume is rejected for finance, hydropower, and insurance sector at a $5 \%$ level. Therefore, there is statistically significant causality in the finance, hydropower, and insurance sector running from stock returns to trading volume. Development banks, hotels, and other sectors are without evidence of any causal effect. This study also finds that there is no evidence of bidirectional causality relationship in any sector of the Nepalese stock market 
which supports the results of a study conducted by Pisedtasalasai and Gunasekarage (2007) for five Asian tiger countries.

\section{Conclusions and implications}

Based on the time series data analysis, it is concluded that there is no evidence of any causal relationship between stock returns and trading volume in the overall Nepalese stock market. There is a unidirectional causality in the case of sector-wise study ranging from trading volume to stock returns in commercial banks and stock returns to trading volume in finance, hydropower, and insurance sectors. Development banks, hotels, and other sectors are without evidence of any causal effect This study also finds that there is no evidence of bidirectional causality relationships in any sector of the Nepalese stock market. future researchers in this area, and national economic policymakers to study the behavior of the Nepalese stock market. This study has investigated the relationship between stock returns and trading volumes using OLS. There is further scope for a future study taking other variables like policy effect, the effect of political events, seasonality effect, and festival effects using a more sophisticated time series model.

\section{References}

Admati, A. R., \& Pfleiderer, P. (1988). A theory of intraday patterns: Volume and variability. The Review of Financial Studies, 1(1), 3-40.

Andersen, T. G. (1996). Return volatility and trading volume: An information flow interpretation of stochastic volatility. The Journal of Finance, 51(1), 169-204.

Bhagat, S., \& Bhatia, S. (1996). Trading volume and price variability: Evidence on lead-lag relations from granger-causality tests. Available at SSRN 7308.

Blume, L., Easley, D., \& O' Hara, M. (1994). Market statistics and technical analysis: The role of volume. Journal of Finance, 49(1), 153-182.

Chen, Firth, \& Yu. (2004). The price-volume relationship in China's commodity futures markets. The Chinese Economy, 37(3), 87-122.

Chordia, T., \& Swaminathan, B. (2000). Trading volume and cross-autocorrelations in stock returns. The Journal of Finance, 55(2), 913-935.

Clark, P. K. (1973). A subordinated stochastic process model with finite variance for speculative prices. Econometrica: Journal of the Econometric Society, 41(1), 135-155.

Copeland, T. E. (1976). A model of asset trading under the assumption of sequential information arrival. The Journal of Finance, 31(4), 1149-1168.

De Medeiros, O.R. \& Van Doornik, B.F.N. (2008). The empirical relationship between stock returns, return volatility, and trading volume in the Brazilian stock market. Brazilian Business Review, 5(1), 1-17. 
Deo, M., Srinivasan, K., \& Devanadhen, K. (2008). The empirical relationship between stock returns, trading volume, and volatility: Evidence from selected Asia-Pacific stock market. European Journal of Economics, Finance and Administrative Sciences, 12, 23-41.

Epps, T. W., \& Epps, M. L. (1976). The stochastic dependence of security price changes and transaction volumes: Implications for the mixture-of-distributions hypothesis. Econometrica: Journal of the Econometric Society, 44(2), 305-321.

Fama, E. F. (1970). Efficient capital markets: A review of theory and empirical work. The Journal of Finance, 25(2), 383-417.

Girard, E., \& Biswas, R. (2007). Trading volume and market volatility: Developed versus emerging stock markets. The Financial Review, 42 (3), 429-459.

Harris, L. (1986). Cross-security tests of mixture of distribution hypothesis. Journal of Financial and Quantitative Analysis, 21(1), 39-46.

Harris, M., \& Raviv, A. (1993). Differences of opinion make a horse race. The Review of Financial Studies, 6(3), 473-506.

He, H., \& Wang, J. (1995). Differential information and dynamic behavior of stock trading volume. The Review of Financial Studies, 8(4), 919-972.

Hiemstra, C., \& Jones, J. D. (1994). Testing for linear and nonlinear Granger causality in the stock price-volume relation. The Journal of Finance, 49(5), 1639-1664.

Jennings, R. H., \& Barry, C. B. (1983). Information dissemination and portfolio choice. Journal of Financial and Quantitative Analysis, 18(1), 1-19.

Karpoff, J. M. (1987). The relation between price changes and trading volume: A survey. Journal of Financial and Quantitative Analysis, 22(1), 109-126.

Kyle, A.S. (1988). Trading halts and trading limits. Review of Futures Markets, 7, 136-175.

Lamoureux, C. G., \& Lastrapes, W. D. (1990). Heteroskedasticity in stock return data: volume versus GARCH effects. The Journal of Finance, 45(1), 221-229.

Mestel, R. Gurgul, H., Majdosz, P. (2005). The empirical relationship, between stock returns, return volatility, and trading volume on the Austrian stock market. The University of Graz, Institute of Banking and Finance.

Morse, D. (1980). Asymmetrical information in securities markets and trading volume. Journal of Financial and Quantitative Analysis, 15(5), 1129-1148.

Pisedtasalasai, A., \& Gunasekarage, A. (2007). Causal and dynamic relationships among stock returns, return volatility, and trading volume: Evidence from emerging markets in South-East Asia. Asia-Pacific Financial Markets, 14(4), 277

Ratner, M., \& Leal, R. P. (2001). Stock returns and trading volume: Evidence from the emerging markets of Latin America and Asia. Journal of Emerging Markets, 6(1), 5-22. 
Ravi Kant (2011). Testing of relationship between stock return and trading volume in India. International Journal of Multidisciplinary Research, 1(6),371-393.

Shrestha, S.R. (2011). Stock returns and trading volume in Nepal. SEBON Journal.

Smirlock, M., \& Starks, L. (1988). An empirical analysis of the stock price-volume relationship. Journal of Banking \& Finance, 12(1), 31-41.

Tauchen, G. E., \& Pitts, M. (1983). The price variability-volume relationship in speculative markets. Econometrica: Journal of the Econometric Society, 51(2), 485-505.

Varian, H. (1985). Divergence of Opinion in Complete Markets: A Note. Journal of Finance, 40(1)309-317.

Wang, J. (1994). A model of competitive stock trading volume. Journal of Political Economy, 102(1), 127-168. 